\title{
An Austrian view of the 2017 consensus for the treatment of early breast cancer
}

\author{
Guenther G. Steger
}

Received: 24 August 2017 / Accepted: 25 August 2017 / Published online: 12 September 2017

(C) Springer-Verlag GmbH Austria 2017

As the recently appointed Chair for Medical Breast Cancer Research at the Medical University of Vienna which is the first of its kind in the German-speaking world and which was established by the university due to the ever growing importance of breast cancer oncology, I was invited to write this editorial for MEMO's series on breast cancer appearing in this issue of the journal.

The biannual St. Gallen International Breast Cancer Conferences (held in Vienna since 2015) are important meetings for breast cancer oncologists to review, discuss, and also develop the current scientific knowledge and its practicability to be translated and used in the daily clinical routine for treating and diagnosing patients with early breast cancer. However, according to the subtitle of these conferences "Evidence, Controversies, Consensus" they are not meant to provide simple "cooking recipes" for patients and their physicians but rather to give some guidance for appropriate decision making were current standards end and areas of uncertainty exist: based on the presentations of the most recent preclinical and clinical trial data tional breast cancer researchers during the first three days of each conference, the fourth day is dedicated to the "Consensus" for problems and open questions in treating early breast cancer when more than 40 international experts from all fields and specialties dealing with breast cancer are voting on predefined questions. Naturally, due to this way of deciding on topics which are not clearly to be answered based on sciwhich are given by some of the most expert interna-

entific data, these results or recommendations of the St. Gallen panel can only be viewed as lowest common denominator of the panel participants which is then summarized, compiled, sometimes interpreted, and finally published several months later in the $A n$ nals of Oncology by an also predefined writing committee [1]. Clearly, this way of finding a "consensus" on current unanswered but clinically meaningful and important questions which is for a good part based on the-sometimes small-majority of opinions immediately leads to discussions and more open questions of course mostly on a much higher scientific level. Thus, it is also a long-standing tradition in Austria that immediately after each St. Gallen Breast Cancer Conference a symposium under the heading "Data + Facts: Consequences?" is organized to report, summarize, and most importantly interpret these results from a national point of view by some of the most expert Austrian breast cancer specialists.

In this issue of the MEMO journal, we are now trying to compile these Austrian interpretations and opinions of the 2017 St. Gallen Conference in Vienna by presenting short reviews and statements of the medical [2], surgical [2, 3], and gynecological [2], as well as the radiodiagnostic [4] perspectives in order to provide European specialists as well as the nonspecialized interested readers with a comprehensive overview of the current status and the open questions of the diagnosis and treatment of early breast cancer.

Conflict of interest G.G. Steger declares that he has no competing interests.

\section{References}

Chair for Medical Breast Cancer Research, Comprehensive

Cancer Centre and Gaston H. Glock-Research Centre,

Department of Internal Medicine I, Medical University of

Vienna, Waehringer Guertel 18-20, Vienna, Austria

guenther.steger@meduniwien.ac.at
1. Curigliano G, Burstein HJ, Winer EP, Gnant M, Dubsky P, Loibl S, Colleoni M, Regan MM, Piccart-Gebhart M, Senn H-J, Thürlimann B, Panel Members of the St. Gallen Inter- 


\section{editorial}

national Expert Consensus on the Primary Therapy of Early Breast Cancer. De-escalating and escalating treatments for early-stage breast cancer: the St. Gallen International Expert Consensus Conference on the Primary Therapy of Early Breast Cancer 2017. Ann Oncol. 2017;28(8):1700-12.

2. Pfeiler G, Bartsch R, Fitzal F. Highlights from the 2017 St. Gallen Breast Cancer Consensus. Memo. 2017;10. https:// doi.org/10.1007/s12254-017-0349-x.

3. Exner R. Local therapies for breast cancer. Memo. 2017;10. https://doi.org/10.1007/s12254-017-0336-2.
4. BaltzerPAT,KapetasP,Marino MA,ClauserP.Newdiagnostic tools for breast cancer. Memo. 2017;10. https://doi.org/10. 1007/s12254-017-0341-5.

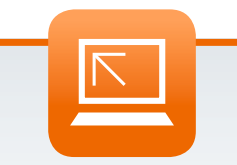

- For latest news from international oncology congresses see: http://www.springermedizin.at/ memo-inoncology 